\title{
THE HABITS AND FEEDING ORGANS OF DENTALIUM ENTALIS
}

\author{
By J. E. MORTON \\ Department of Zoology, Queen Mary College, University of London
}

(Text-figs. $\mathrm{I}-5$ )

The Scaphopoda or tusk-shells are the smallest and most uniform class of molluscs. They burrow in sand of medium to coarse shelly grade, and specialize on a diet of hard-shelled microbenthos, particularly Foraminifera. Dentalium entalis L. is the commonest West European species, and may become locally dominant. Le Danois (1948) has described a 'Dentalietum' in deeper water sandy ground at about 100 fathoms in the southern Celtic Sea. Stephen (1933) discusses the distribution of $D$. entalis in the northern North Sea, where it is largely restricted to the 'Offshore zone', the southern limit being marked by the $60 \mathrm{~m}$ line. Low salinity is probably responsible for its absence from the southern North Sea; and in general it seems limited more by hydrographic conditions than by the relative abundance of foraminiferan food. For example, in Stephen's Thyasira + Foraminifera Zone, it is no more than sparsely present. Holme (1953) finds Dentalium entalis rare or absent near Plymouth, though it was relatively common at the Eddystone Grounds at the end of last century (Allen, 1899). It has today receded to the mouth of the Channel, in coarse deposits resulting from fairly strong scour, and Holme suspects it to be one of the list of species sensitive to recent hydrographic changes in the area.

For the living material used in this study I am greatly indebted to $\mathrm{Mr} \mathrm{N}$. A. Holme, who collected it in deeper water in the Celtic Sea on a 1953 cruise of the R.R.S. 'Discovery II'. With it were collected Chlamys opercularis, Caryophyllia and in places Astropecten irregularis; there were also many of the tusk-shaped serpulid tube worm Ditrupa arietina which as I found can impose a neat deception on the uncritical hunter for scaphopods.

Dentalium entalis survived for some months in fairly clean sand of medium grade under circulation in the laboratory, settling happily only when it was able to burrow obliquely into the substrate with about a centimetre of the narrow tip exposed. As Yonge (1937) has shown, both the inhalant and exhalant pallial currents pass through the small pallial tube that projects at that end of the shell. Apart from Yonge's paper on the ciliary currents and water circulation of the pallial cavity, little has been published in detail on the mode of life of scaphopods, though it has been known for many years, at least 
since Clark (1849), that they feed on Foraminifera. The purpose of this paper is to give a more detailed account, from living material, of the organs responsible for capturing and digesting food.

The concavely curved side of the shell is dorsal and in burrowing-whatever way it begins-the animal will soon twist until the dorsal side is uppermost in the obliquely buried position (Fig. I F). When Dentalium is withdrawn into its shell the mantle cavity is closed in front except for a narrowly constricted central pore; within this, the tongue-shaped foot is retracted,

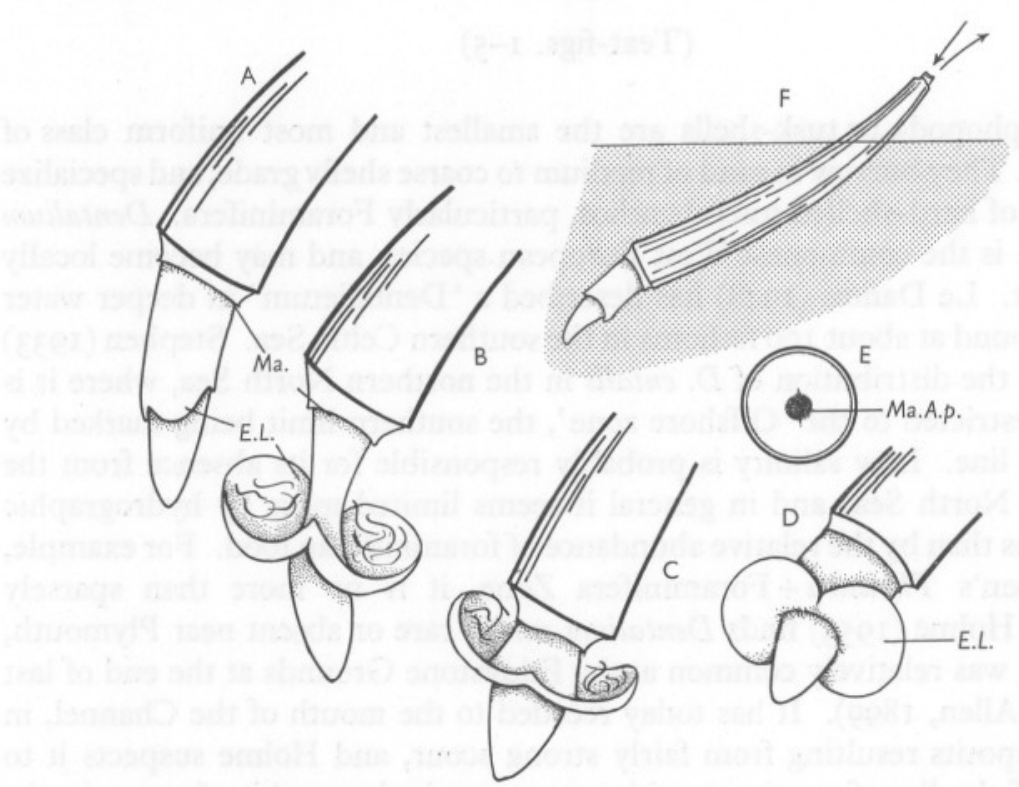

Fig. I. Dentalium entalis: A, B, C, successive stages in the burrowing of the animal, showing the action of the foot and its extensible lobes. D, the extended foot viewed more anteriorly. $\mathrm{E}$, the anterior end with the foot retracted showing the contracted pallial aperture. F, the shell and animal in natural posture in the sand. E.L., extensible side lobes of the foot; Ma., edge of the mantle with its aperture distended; Ma.A.p., contracted pallial aperture.

forming a slightly curved muscular column lying ventrally to the head and filling most of the anterior third of the mantle cavity. As burrowing begins, the foot is protruded through the mantle pore as a firmly pointed lobe, which extends until it is fully external, encircled by the widely distended mantle orifice around its base. The foot has an erectile fold of skin, narrowest in the mid-line above and below and expanding into broad rounded lobes at either side. As the tip of the foot is plunged into the ground at each burrowing stroke these side lobes are retracted, until of small size, pressed close to the foot and forced into the sand with it. The extended foot is then engorged with blood from the general haemocoele, and the lobes are strongly erected, their edges being recurved to form a wide circular flange, anchoring the animal firmly in 
the loose substrate. The stalk of the foot is now shortened as the shell is drawn up behind, and it is usually at the first such move that a twist is made through up to $90^{\circ}$ as the animal orients dorsal side up. When the animal is suitably embedded the foot is partly retracted through the dilated pore of the mantle, and the animal puts out large numbers of the delicate cephalic appendages or captacula, which thrust their way in all directions through the surrounding sand.

\section{THE CAPTACULA}

These filiform prehensile tentacles arise in a dense bunch, from a single lobe (which may be partly divided) at the outer base of the proboscis on either side. Each is enlarged at its tip into a small ovoid or flattened bulb. They can elongate greatly as they are protruded and show a great deal of autonomous writhing movements when detached, but when retracted they lie in a compact cluster at either side between the proboscis and the mantle wall. They vary somewhat in number (in a typical cluster I counted about I35 on one side) and also in size; some, in the resting state, reach to the tip of the foot, othersprobably recently regenerated-are short and their bulbs almost sessile. Extrusion takes place by the inflow of blood, and the captacula radiate in large numbers like the finest of strands through the substrate; rapid withdrawal is achieved by the contraction of their longitudinal muscle fibres. Though their action has never been described fully, they constitute the only food-catching organs, searching out and skilfully locating Foraminifera: there is seldom any admixture of detritus or of other living animals with the diet, and the Dentalium seems a strongly specialist feeder, though-as Clark (1849) has mentioned-it may sometimes vary its diet with bivalve spat or large diatoms. Once or twice I found the broken-off tip of a captaculum among the contents of the proboscis, still attached to a foraminiferan; and Dell (1957) has for a New Zealand species found Foraminifera entangled in the extruded captacula, as well as in the proboscis. Dentalium is nevertheless so shy in captivity that I could never once observe it in the act of taking food, and I can find no account in the literature bearing the stamp of actual observation.

For some understanding of the way the captacula work we need an account of their anatomy. From the size of these organs in relation to the bulk of a foraminiferan it seems a fair inference that a group of captacula comprising some numbers must attach together to each organism to be hauled in. Fol (I889) has given an account of the structure of the captacula with which I must in some points disagree. Each tentacle-as he showed clearly-is provided with means of extension and retraction and contains at its tip secretory glands, a ganglion and sensory receptors. Through the filament runs a central bloodfilled cavity connected with the haemocoele of the head and surrounded by a layer of strong and regular longitudinal muscle fibres, usually ten in number. The central cavity has no internal epithelium as figured by Fol: the small 


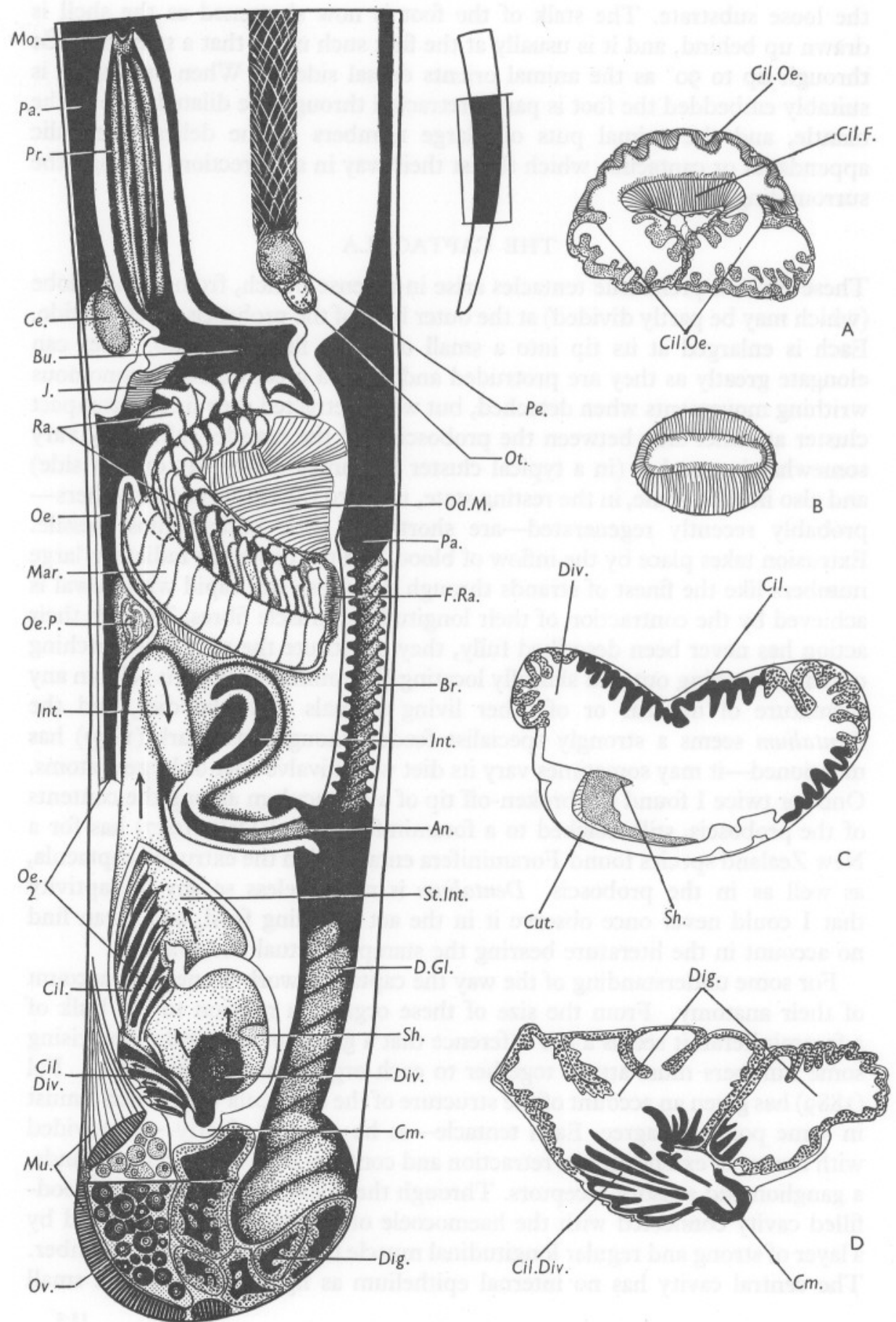

Fig. 2 
dark-staining ovoid nuclei appearing there belong to blood amoebocytes or to a thin reticulum of connective tissue, especially concentrated near the slender nerve that runs through one side of the cavity. No circular muscles can be found; instead the filament is invested at close intervals by extremely slender connective tissue fibres. These are overlaid by a delicate squamous epidermis whose elongate nuclei run transversely to the filament. When the filament is contracted these cells stand out as regularly spaced annulae along its surface. The captaculum shows a rather close parallel to the echinoderm tube foot, now well understood from the work of Smith (1947), and forming essentially a tentacle with a hydroskeleton, longitudinal muscles and an outer circular investment of collagen. During elongation (in Dentalium by blood, in echinoderms by ambulacral fluid) increase in diameter is moderated by the limited elasticity of the circular elements while the longitudinal muscles are extended. When the longitudinal muscles contract to bring about retraction, the circular fibres must be sufficient to prevent distention of the wall by fluid under pressure, the attenuated cylinder having a minimal ratio of volume to restraining wall surface.

In none of the numerous sections examined could I find any trace of Fol's 'bandelette vibratile longitudinale' on one flattened side of the filament. The epidermal cells run right round the filament and it is difficult to see how such

\section{Legend to Fig. 2}

Fig. 2. Dentalium entalis. Left. Somewhat schematic view of the middle part of the body, displaying the left half in approximate sagittal section to illustrate the course of the alimentary canal and its relation to the surrounding structures. The dorsal side is to the left. At the posterior end, the left half of a transverse section is, revealed, with the retractor muscle and ventral mantle wall continuing a little to the right of the middle line. A portion of the oesophagus is omitted, where it inclines to the right before entering the stomach. $\times$ Io. Inset. The shell at natural size, showing the extent of the parts illustrated. Right. Transverse sections of successive parts of the alimentary canal. A, the oesophagus, through the region of the oesophageal pouches; $\mathrm{B}$, the oesophagus behind the pouches; $\mathrm{C}$, the stomach, near the anterior limits of the digestive diverticulum; D, the posterior end of the stomach passing through the caecum and adjacent digestive gland and cutting tangentially the ciliated tracts associated with the caecum and diverticula. $A n$., anus; $B r$., folds of the mantle wall serving as the respiratory organ; Bu., buccal cavity; Ce., cerebral ganglion; Cil., ciliated fold of the roof of the stomach leading to the intestine; Cil.Div., ciliated folds associated with the caecum and digestive diverticula; Cil.F., ciliated fold of the glandular region of the oesophagus; Cil.Oe., ciliated lining of the oesophagus; $\mathrm{Cm}$., caecum of the stomach; Cut., cuticulated epithelium of the stomach; D.Gl., digestive gland tubules spreading round the side of the mantle cavity; Dig., digestive gland in section; Div., digestive diverticulum leading from stomach; F.Ra., formative cells of the radula at the bottom of the radular sac; Gl.Oe., limits of the glandular region of the oesophagus; Int., intestine; $\mathcal{F}$., jaw; Mar., marginal teeth of left side within the radular caecum; Mo., mouth; $M u$., retractor muscles attached posteriorly to the shell; Od.M., muscles of the odontophore; Oe., oesophagus; Oe.P., oesophageal pouch; Oe. 2, extent of interrupted section of the oesophagus; Ot., otocyst; Ov., ovary; $\mathrm{Pa}$., pallial cavity; Pe., pedal ganglion; $P r$., proboscis, $R a$., radula (lateral teeth of left side and median teeth); Sh., vestige of gastric shield; St.Int., anterior part of stomach, tapering forward to intestine. 
a ciliated tract could be maintained with continual alterations of length, or what function it could perform.

The tip of the captaculum (Fig. 3A)-unlike the filament-is ciliated all over, but especially densely in a subterminal alveolus or shallow depression lying on one side, where the cilia are twice as long as elsewhere. The interior of the terminal bulb is filled mostly by a close-packed mass of ovoid darkstaining epidermal nuclei, surrounding near the centre a small ganglion presumably connected with the captacular nerve. Associated with this ganglion

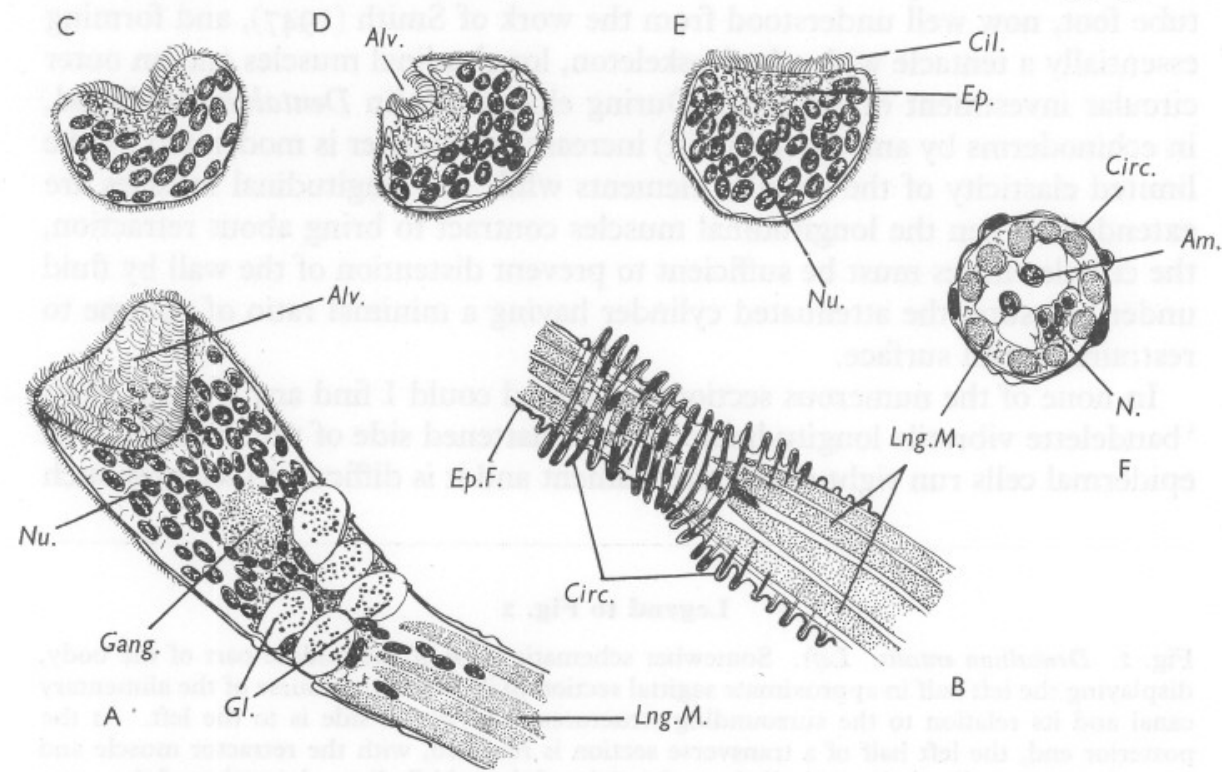

Fig. 3. Dentalium entalis. Histology of the captacula, from sections cut at $5 \mu$ and stained in iron haematoxylin or in Heidenhain's azan. A, the tip of a captaculum in tangential section, showing part only of the ciliated alveolus, the ganglion and the nest of gland cells; $\mathrm{B}$, tangential longitudinal section of part of a filament showing the arrangement of longitudinal muscles and circular connective tissue; C, D, E, transverse sections of the terminal bulb with different conditions of the ciliated alveolus, from contraction to the flatly expanded state; $\mathrm{F}$, transverse section of a filament. Am., amoebocyte in lumen; Alv., alveolus; Cil., cilia; Circ., circular connective tissue; $E_{p}$., epithelium of the alveolus; $E_{p} . F$., epithelium of the filament; Gang., ganglion; Gl., glands; Lng.M., longitudinal muscle; $N$., nerve; $N u$., nuclei of epithelial and sensory cells of terminal bulb.

Fol clearly figures rod-like end-organs between the columnar cells lining the alveolus. At the base of the terminal bulb where the longitudinal muscles taper off, lies a nest of plump-bodied epidermal glands, with basal nuclei and their contents non-staining save for clusters of granules which become red in azan and black in iron haematoxylin. Some of these glands were seen in sections to be discharging at the surface of the epidermis.

By what means can the captacula take hold of a foraminiferan test? It is unlikely from their situation that the gland cells help in prehension; it is 
tentatively suggested these may produce a toxin disabling living Foraminifera, or even a repugnatorial secretion protecting the animal's own widely deployed and otherwise vulnerable captacula. There are no obvious prehensile structures, in the form of organised suckers. A viscous secretion seems unlikely, from the histological structure of the bulbs, and although the filament can sometimes coil, it is impossible to visualize it as an entwining tentacle. As shown in Fig. 3, the subterminal depression of the bulb may be contracted to a deep cup, or be opened out shallowly, or perfectly flat in its full state of expansion. These changes of shape must be secured by a fine intrinsic musculature, which was, however, quite obscured by the crowded nuclei in the preparations illustrated. Closely applied to the foraminiferan test, when flattened out, the depression could provide a temporary but quite effective suction cap. Several captacula acting in concert could obviously exert a significant pull quite adequate to bring the foraminiferan to the mantle cavity and thence to the mouth. By its coat of cilia the tip of the captaculum might be moved over the surface of the test, exploring it for position before taking up its attachment. A parallel to such a mode of attachment is already known, in the tentacles of the terebellid polychaete worms, as carefully described by Dales (1955). These though much larger have a somewhat comparable structure, each forming a long, very extensible fluid-filled appendage traversed by longitudinal muscles. Instead of a terminal depression they have a ciliated groove all the way along; this can be applied locally to the substrate and creep along by its cilia, and, when the groove is locally flattened out, the tentacle can take a firm hold of the ground at any point along its length.

\section{ALIMENTARY CANAL}

The gut begins with a flattened muscular-walled proboscis, contractile but not inversible, projecting from the head dorsally to the foot and lying in front of the buccal mass between the bunches of captacula. The mouth is a horizontal slit running across the anterior end of the proboscis, and its sides are drawn out to give it a wide crescentic form. It has thickened, crenulated lips, and when the captacula are withdrawn into the mantle cavity, the tips of the longest come to lie about level with the mouth. From the position of some captacula in fixed material, it seems they may be drawn through or between the parted lips, as their attached load is ingested. After feeding, the muscular wall of the proboscis is then stretched quite thin, and its cavity is crammed with the tests of living Foraminifera, which bulge out all over its surface like small close-set pustules or sometimes angular projections. When full, it was found to contain a dozen or so large tests (up to $350 \mu$ ), three or four times as many small ones, and almost nothing more. Such fine power of selectivity is a testimony to the searching efficiency of the captacula. An occasional diatom frustule may be picked up, and at times empty foraminiferan tests, but the 
great bulk of the meal is of living Foraminifera, all perfectly intact in the proboscis, trituration taking place further back in the gut. A specimen from the Celtic Sea, with the proboscis full, had for example collected the following haul:

Elphidium sp. (=Polystomella), the largest and commonest species, about six tests up to $350 \mu$, and many smaller ones.

Quinqueloculina sp., a miliolid, two large tests $(200 \mu)$ and a number of small. Discorbis (?) sp., a trochoid rotaliid.

Globigerina test, apparently empty when picked up and not recorded living in this area.

A Millport preserved specimen examined for comparison had the proboscis filled with a single species of Bulimina.

I am indebted to Dr R. H. Hedley for identifying the Foraminifera as accurately as possible after decalcification resulting from fixation.

Behind the proboscis lies a buccal mass, of about the same length but much deeper and more muscular. The proboscis is very contractile and may empty its contents by peristalsis, while removal of Foraminifera may be helped by the radula which is so situated that its lateral teeth when protracted could haul whole frustules, perhaps several at a time into the buccal mass. Fig. 4 shows the relative size and proportions of the radula, typical foraminiferan tests, and captacular bulb. The radula is relatively immense by comparison with the rest of the gut, and is proportionately larger than in any other mollusc I have seen. It has approximately 18 rows of teeth, each bearing 5 teeth. The central tooth is a crescentic transverse plate with no sharp cusps. It is flanked at each side by a strongly falcate lateral tooth, and outside that by a smooth marginal tooth, little more than a broad plate of chitin paving the side of the odontophore. The radula has the usual morphological relations: it lies in a narrow groove at the centre of the odontophore, and is spread out for protection, and afterwards retracted, by muscles attached to an odontophoral skeleton of two 'cartilages'. The laterals are the main functional teeth, and their distal expansions are wide and hood-shaped behind the sharp tip. A foraminiferan test grasped by them and lifted up towards the roof of the buccal mass might then be engaged between the strong bar of the central tooth and the chitinous jaw. This is a median, bow-shaped plate, running across the front wall of the buccal mass. As well as transferring Foraminifera from the proboscis to the oesophagus, the radula may thus also have acquired the task of fracturing and triturating them. This would accord with its uniquely large size in Dentalium, the lack of other hard triturating surfaces farther back, and absence, in my material, of any intact frustules in later parts of the gut. Clark, however, mentions finding them in the stomach, and the very contractile stomach wall must play some part as a gizzard when distended by the food mass.

Of the rest of the gut the chief features for remark are the absence of mucus 


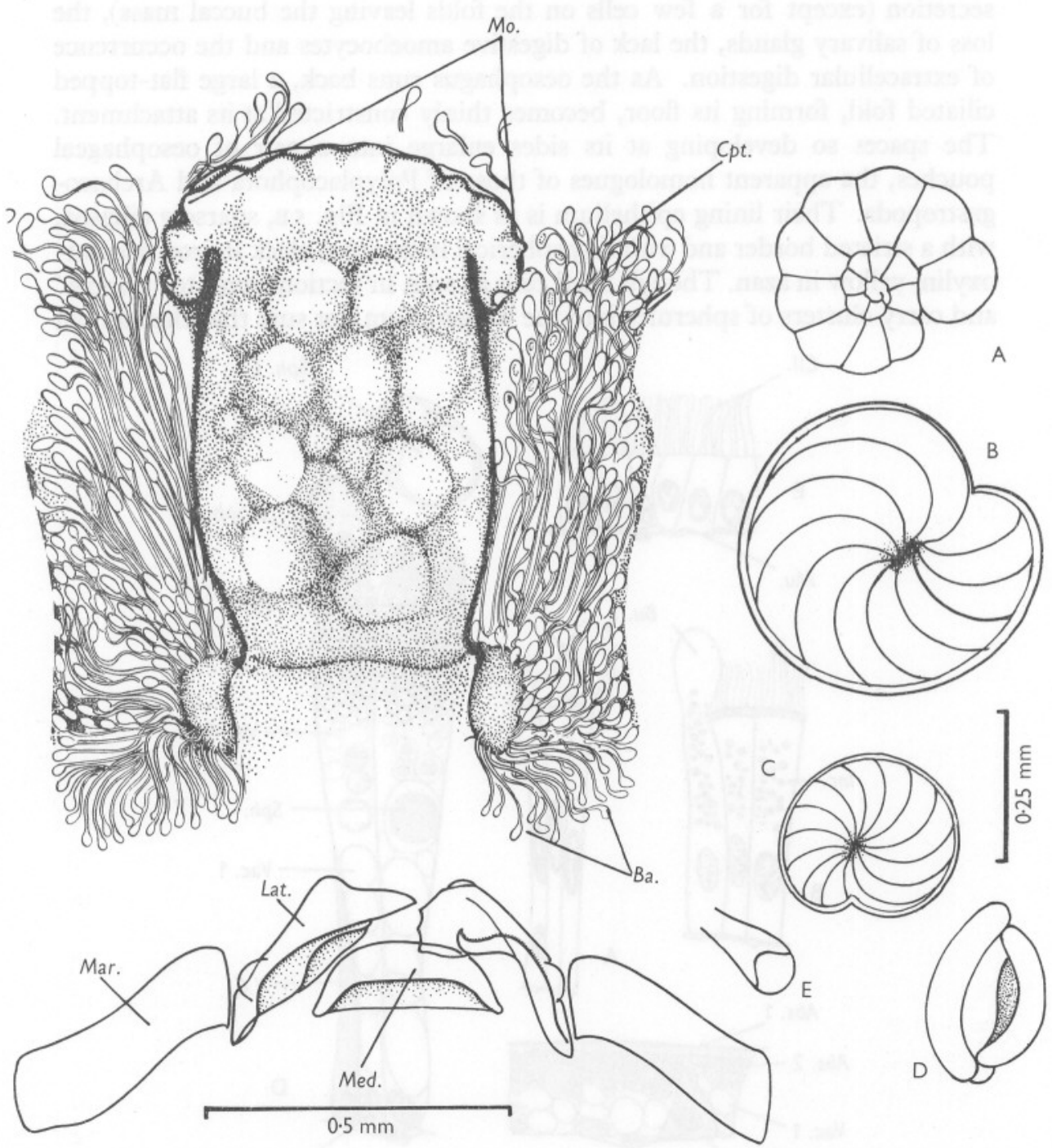

Fig. 4. Dentalium entalis. Upper left. The proboscis and the bunches of retracted captacula viewed from above, after the removal of the dorsal mantle wall. Ingested foraminiferans bulge through the wall of the proboscis. Lower left. A single row of teeth from the radula. Right. To the same scale as the radula are shown outlines of representative foraminiferans found in the proboscis: A, Discorbis sp.; B, C, Elphidium sp. of different sizes; D, Quinqueloculina. The tip of a captaculum, E, is also represented to the same scale. $B a$., short captacula at the base of the cluster; Cpt., captacula; Lat., lateral tooth; Mar., marginal tooth; Med., central tooth; Mo., extent of mouth. 
secretion (except for a few cells on the folds leaving the buccal mass), the loss of salivary glands, the lack of digestive amoebocytes and the occurrence of extracellular digestion. As the oesophagus runs back, a large flat-topped ciliated fold, forming its floor, becomes thinly constricted at its attachment. The spaces so developing at its sides enlarge into a pair of oesophageal pouches, the apparent homologues of those of Polyplacophora and Archaeogastropoda. Their lining epithelium is as shown in Fig. 5B, sparsely ciliated, with a striated border and with tiny spherical inclusions, black in iron haematoxylin, yellow in azan. Though fixed cells as seen in sections tend to 'bubble' and carry clusters of spherules into the lumen, I am not sure that they are an

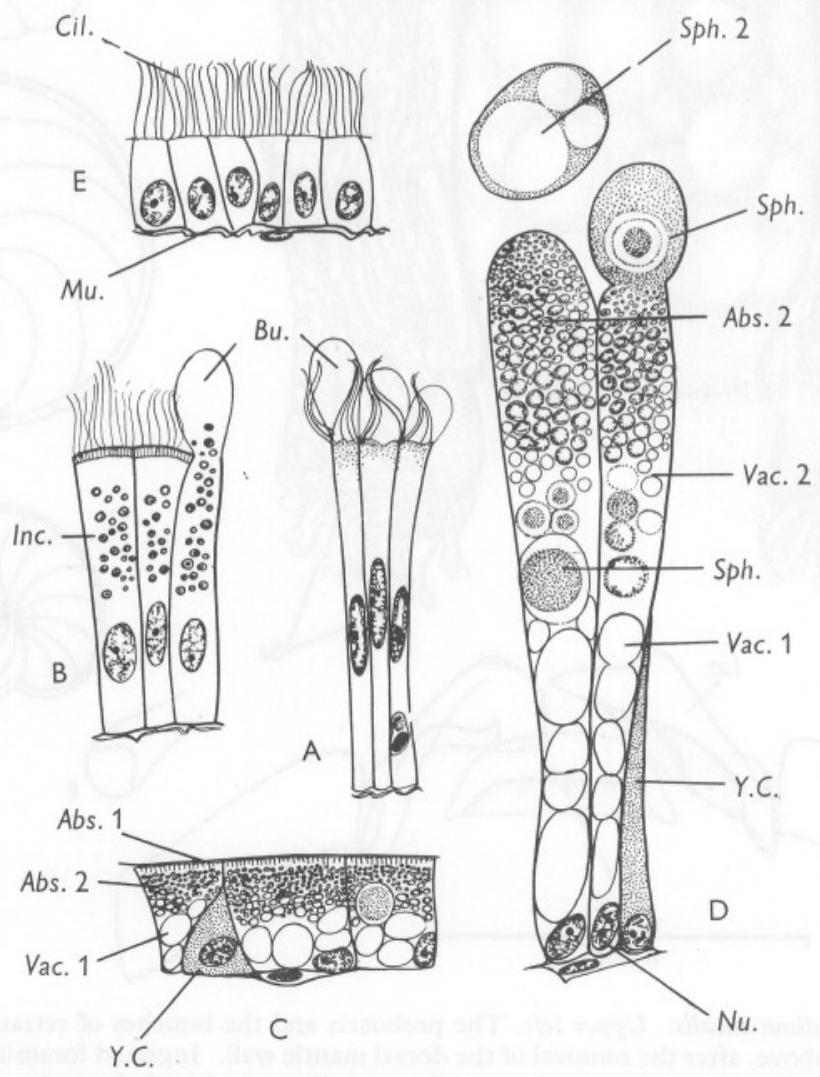

Fig. 5. Dentalium entalis. Histology of the alimentary canal. A, ciliated cells of the oesophagus; B, glandular cells of oesophageal pouch; C, cells of digestive gland at early absorbing stage; $\mathrm{D}$, digestive cells of maximum size at late stage, producing 'secretory' spheres; $\mathrm{E}$, cells of intestine. Abs. I, finely striated flat absorbing surface of the digestive cell; $A b s .2$, absorbed material not yet enclosed in cell vacuoles; $B u$., 'bubbling' cytoplasm of oesophageal cell; Cil., cilia; Inc., granular inclusions in oesophageal cell; $M u$., muscle fibre; $N u$., nucleus; $S p h$. I, sphere rounding off at tip of mature digestive cell; Sph. 2, sphere cut off from cell; Vac. I, colourless vacuoles towards base of cell; Vac. 2, digestive vacuoles with absorbed contents; Y.C., young cell. 
important source of secretion in life-similar types of inclusions may indeed be seen in the non-glandular cells beneath the cuticle of the stomach. Behind these pouches the oesophagus narrows to run as a ciliated tube to the right side of the stomach, close to where the intestine emerges towards the left.

The stomach, though thin-walled, has a muscular tunic and performs vigorous contractions in life. It probably serves chiefly as a gizzard into which open posteriorly at either side the very wide, almost symmetrical, apertures of the paired digestive diverticula. The stomach is a globular or pyriform sac, with little more than half the volume of the buccal mass, and tapers towards the oesophagus and intestine in front. Its structure, viewed in Fig. 2, shows disappointingly little of the primitive architecture of the molluscan stomach, though there are two features that would pass unnoticed but for an awareness of the past history of this organ. A small conical papilla, ciliated inside, and projecting behind the digestive diverticula is evidently a relic of the posterior gastric caecum. Immediately to the right and left of it begin the apertures of the respective digestive diverticula; and from the caecum as a centre point a series of ciliated ridges radiate over the posterior end of the stomach. Some of these extend to the thresholds of the diverticula, while most run up to the dorsal side of the stomach, slanting towards the intestine and terminating at the summit of a flat triangular fold (Fig. 2C, D). Their ciliation is simple, producing a set of currents leading along the grooves towards the intestine. These are the only ciliary movements within the stomach: cuticle covers the floor and such part of the side-walls as is not perforated by the two diverticula. The floor is raised at one point into a small spur of cuticle, the second relic of the primitive stomach, which represents a vestige of the gastric shield.

No trace of style-sac ciliation survives, and material from the stomach is periodically squeezed into the intestine by peristalsis, in a loosely compacted rope formed of the remains of Foraminifera, held together by the viscous outflow from the digestive gland. The intestine describes a double loop in the space between the stomach and buccal mass, the rectum then descending to open in the ventral mid-line into the pallial cavity immediately behind the region of the respiratory folds. The faeces are not bulky and are not compacted into separate firm pellets. The intestinal lining cells (Fig. 5E) are shortly columnar with sparse longish cilia; and I could find no secretory cells.

\section{DIGESTIVE GLAND}

The digestive gland clearly secretes enzymes for extracellular digestion, as can be judged by the bulky nature of the food, its complete breakdown in the stomach, and the lack of any other enzyme sources with the very doubtful exception of the small oesophageal pouches. The gland is also the site of absorption. It is built up of tubules closely adpressed with little or no intervening connective tissue. Each common diverticulum opens straight out of 
the stomach, to break into a row of thick, finger-shaped tubules on either side. The right and left lobes of the digestive gland so formed unite in a median dorsal bridge over the mantle cavity and beneath the gonad. In either lobe, the series of tubules becomes smaller towards the front and the back of the lobe, and spreads round the mantle cavity, except for a median ventral strip which is thin and transparent.

The digestive cells absorb fluid and fine suspended material carried into the tubules by muscular contractions in the stomach. They show in local regions all stages between the two extremes of shape and size in Fig. 5C-D. The first stage is low and squarish, just beginning to absorb, with large clear basal vacuoles and finely granular vacuoles in the distal cytoplasm, whose contents stain blue or grey in azan, identically with the contents in the lumen. Later cells become greatly attenuated, widening and bulging at the loaded tips. The vacuoles in the basal half are still mostly clear, but distally they are loaded with ingested material. The tips are now rounding into compact spheres that will be nipped off and returned to the stomach, entering in large numbers and easily detectable in the faeces. They rarely contain a nucleus and such 'secretion' is merocrine rather than holocrine. This suggests that the cells may again become absorptive, but the digestive gland is also provided with young 'replacing cells' that have not yet begun to absorb. These are broad-based (5C) or narrowly trangular (5D) with rather large nuclei and uniformly dark-staining cytoplasm. As well as bluish vacuoles (azan) the fragmenting tips of the mature cells occasionally contain a vacuole filled by a single large greenish yellow droplet, probably excretory. The contents of all the extruded vacuoles must represent the residual waste returned to the stomach after digestion and assimilation of food. It must be further assumed that the abstricted spheres also provide, either in their vacuoles or in the residual cytoplasm, such enzymes as are necessary for extracellular digestion. The cells thus pass through a life-history widespread in mollusc digestive cells (see Morton, 1956, and Owen. 1955, for lamellibranchs, where there is usually no secretion, and Bidder, 1950, for cephalopods). In Dentalium the cycle includes absorption, assimilation, extrusion of indigestible and excretory residues, and the provision of extracellular enzymes in advance of the next meal.

The Scaphopoda must have early left the main road of advance, being known as a separate group since Silurian times. They retain a primitive simplicity of the renal organs, absence of separate genital ducts and external fertilization, together with a much more complete gut than in lamellibranchs. Even more than the lamellibranchs they have become deeply committed to burrowing life, and-as in the bivalves - the mouth is raised out of direct contact with the substratum. Feeding, which in most modern lamellibranchs has devolved on elaborate gills and in Nuculacea upon palp proboscides, depends in Scaphopoda upon the unique head appendages, the captacula, and on the 
immensely developed radula, which in the bivalves is entirely lost. The lamellibranch gills and mantle cavity equipped their possessors for lavish and long-continued radiation; the scaphopod captacula, by contrast, at once restricted the possible range of diet and variety of habits-in evolutionary terms they are the badge of failure. Dentalium has no gills; the annular pallial folds are adequate for its respiratory needs, and their powerful cilia sufficient to maintain the inhalant and exhalant posterior currents. With a simplified respiratory system, the circulation is in turn rudimentary; there is no heart, but a simple contractile area of the haemocoele wall near the anus. The rhythmic expansion and contraction of the foot and its periodic charging with blood must have far more influence upon blood circulation than could the relatively feeble action of a heart.

\section{SUMMARY}

The scaphopod Dentalium entalis, studied with specimens from the Celtic Sea, is a specialized burrower in medium to coarse sands and its chief or only diet is of Foraminifera. Burrowing is performed by a muscular, very extensible, tongue-like foot, protruded through the anterior pore of the mantle cavity, and anchored in the sand at each distensible burrowing thrust by erectile side lobes. The foraminiferans are captured by very numerous extensible head tentacles or captacula. These radiate in the substrate and terminate in an expanded bulb, with gland cells, receptors and a ciliated alveolus which is able to be flattened out to provide-it is suggested - an attachment organ. Collected Foraminifera are hauled from the cavity of the proboscis into the buccal cavity by a large, strong radula, and pass along the oesophagus to the stomach. This is simplified in structure with a thin but muscular wall which serves the function of a gizzard. There is a vestigial caecum and gastric shield. The digestive diverticula open very widely from the stomach. Digestion appears to be wholly extracellular, and the digestive tubules are compared in structure with those of other Mollusca. The intestine is a simply coiled tube and the faeces are small and uncompacted.

\section{REFERENCES}

Allen, E. J., I899. On the fauna and bottom deposits near the thirty fathom line from the Eddystone to Start Point. F. mar. biol. Ass. U.K., Vol. 5, pp. 365-542. Bidder, ANNA M., I950. The digestive mechanism of the European squids. Quart. 7. micr. Sci., Vol. 91, pp. I-43.

Clark, W., I849. On the animal of Dentalium tarentinum. Ann. Mag. nat. Hist., Ser. 2, Vol. 4, pp. 32I-30.

DALES, R. P., I955. Feeding and digestion in terebellid polychaetes. F. mar. biol. Ass. U.K., Vol. 34, pp. 55-79.

Danois, E LE., 1948. Les Profondeurs de la Mer. Paris: Payot.

DELL, R. K., I957. A revision of the recent scaphopod Mollusca of New Zealand. Proc. roy. Soc. N.Z., Vol. 84, pp. 56I-76. 
Fol, H., I889. Sur l'anatomie microscopique du Dentale. Arch. Zool. exp. gén., T. 7, pp. 9 I-I 48 .

HoLME, N. A., 1953. The biomass of the bottom fauna in the English Channel off Plymouth. F. mar. biol. Ass. U.K., Vol. 32, pp. I-49.

Morton, J. E., 1956. The tidal rhythm and action of the digestive system in Lasaea rubra. F. mar. biol. Ass. U.K., Vol. 35, pp. 563-86.

OwEN, G., I955. Observations on the stomach and digestive diverticula of the Lamellibranchia. I. The Anisomyaria and Eulamellibranchia. Quart. F. micr. Sci., Vol. 96, 517-37.

SмIтн, J. E., I947. The activities of the tube feet of Asterias rubens. Quart. F. micr. Sci., Vol. 88, pp. I-I4.

Stephen, A. C., 1933. Studies on the Scottish Marine Fauna: The natural faunistic divisions of the North Sea as shown by the quantitative distribution of the molluscs. Trans. roy. Soc. Edinb., Vol. 57, pp. 60I-I6.

Yonge, C. M., 1937. The circulation of water in the mantle cavity of Dentalium. Proc. malacol. Soc. Lond., Vol. 22, pp. 333-8. 